
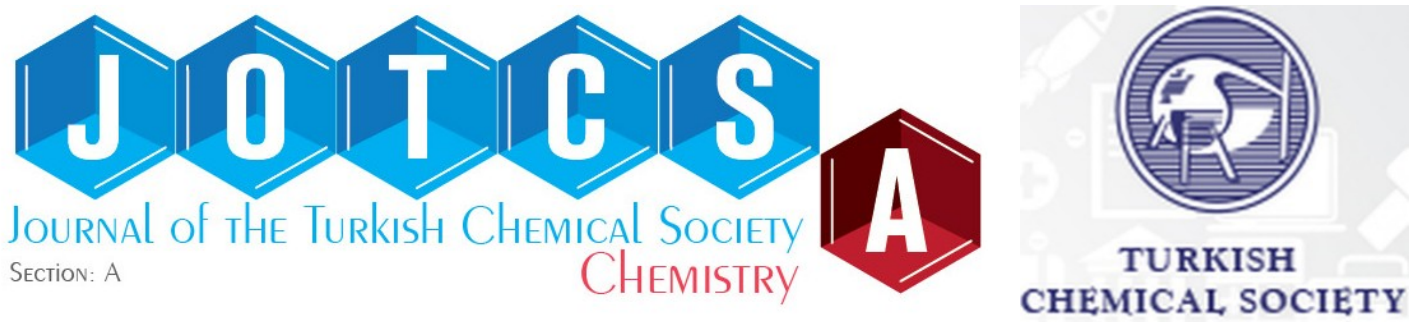

\title{
Calcined Eggshell for the Removal of Victoria Blue R Dye from Wastewater Medium by Adsorption
}

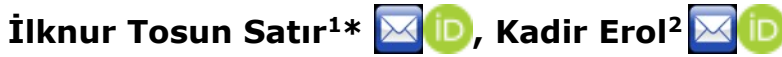

${ }^{1}$ University of Hitit, Faculty of Arts and Sciences, Department of Chemistry, 19040, Corum, Turkey.

2University of Hitit, Vocational School of Health Services, Medical Services and Techniques, 19030, Corum, Turkey

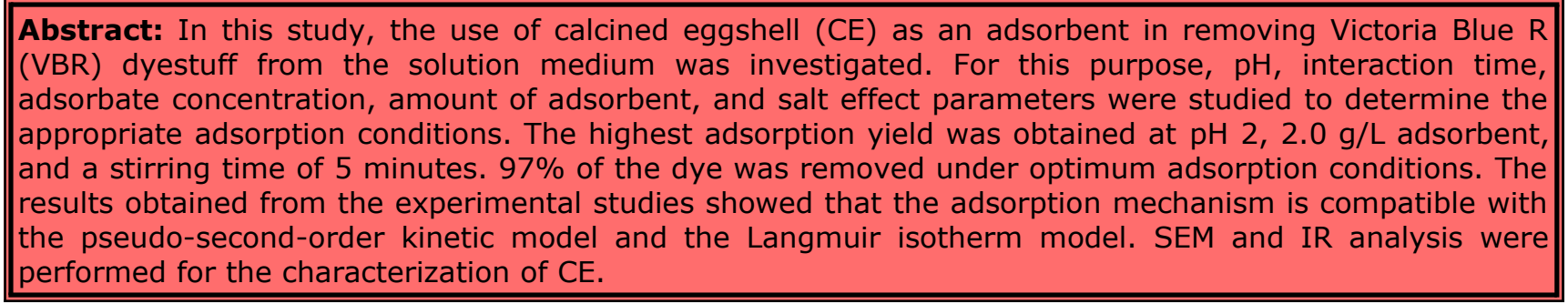

Keywords: Textile dye, calcined eggshell, water treatment, wastewater, adsorption, Victoria Blue R.

Submitted: June 29, 2020. Accepted: November 09, 2020.

Cite this: Tosun Satır İ, Erol K. Calcined Eggshell for the Removal of Victoria Blue R Dye from Wastewater Medium by Adsorption. JOTCSA. 2021;8(1):31-40.

DOI: https://doi.org/10.18596/jotcsa.760083.

*Corresponding author. E-mail: (ilknurtosun@gmail.com), Tel: (+90364 2277000 / 1642), Fax: (+90364 2277005).

\section{INTRODUCTION}

Synthetic dyes used in various industrial applications spread to the environment as a result of industrial activities (1). More than half of the dyes used in the textile industry disappear after dyeing and approximately $10-15 \%$ of the dyes are uptake with liquids. (2). Dyes are synthetic aromatic compounds widely used in textile industries $(3,4)$. It is known that these dyes have mutagenic and carcinogenic effects for aqueous systems and human life. It has also known that some triphenylmethane dyes cause tumoral growth in some fish species (5-8). Also, triphenylmethane dyes have a strong coloring feature and reduce the transparency of the water and gaseous solubility in water (9). Fluids from the paint production industry have higher chemical and biochemical oxygen demand and are significantly colorful (3). As this situation poses a serious risk to people and living organisms in the water, developing an effective method to get away these chemicals from the wastewater is becoming essential.

In order to remove triphenylmethane dyes or contaminants from wastewater; there are many methods, including adsorption, flocculation, electrochemical applications, photo-oxidation, and photocatalytic techniques (10-16). Biosorption is the kind of adsorption used as a biomass adsorbent, it has been widely demanded in recent years $(17,18)$. Victoria Blue R (VBR) is an essential member of the triphenylmethane family of dyes and is extensively used in the industry (19). The removal of the carcinogenic or mutagenic dye from wastewater is of great importance on the environment and human 
health. Various adsorbents have been used from past to present to remove dye from wastewaters (20-23). One of the most commonly used is activated carbon $(24,25)$. However, the regeneration of this material is due to the prolongation of processing times and additional costs. For this, it is necessary to develop alternative disposable adsorbents with no economic value. In line with this idea, eggshell as an agricultural waste has been preferred because it is no-cost and harmless to the environment. The high percentage of calcium carbonate in the eggshell makes it an effective adsorbent (26).

Within the scope of this work to remove the VBR paint from wastewaters, the calcined eggshell powder was used. It has been studied in both continuous and batch systems, and optimum adsorption conditions $(\mathrm{pH}$, contact time, dye concentration, adsorbent dose, temperature, ionic strength) were provided.

\section{EXPERIMENTAL SECTION}

\section{Preparation of Calcinated Eggshells}

Eggshells purchased from a local market were first washed ultra-distilled water, then dried in an oven at $60^{\circ} \mathrm{C}$. Eggshells were calcined in the ash oven at $900{ }^{\circ} \mathrm{C}$. After calcination, the adsorbent was ground with a laboratory grinder and sieved through a 150 $\mu \mathrm{m}$ sieve.

\section{Instrumentation}

After adsorption, the dye concentration remaining in the solution was measured using a Thermo Genesys $10 S$ UV-VIS spectrophotometer at a wavelength of $615 \mathrm{~nm}$. The surface morphology of CE was examined using Scanning Electron Microscopy (SEM); Carl Zeiss AG - EVO® 50 Series, Germany. With the help of double-sided carbon tape, CE was placed on the SEM sample holder surface. It was then coated with a thin layer of gold under vacuum and examined for surface morphology. The functional groups on the surface structure of $C E$ were analyzed using a Fourier Transform Infrared Spectrometer (FTIR) (Thermo Nicolet iS10 FTIR Spectrometer, USA).

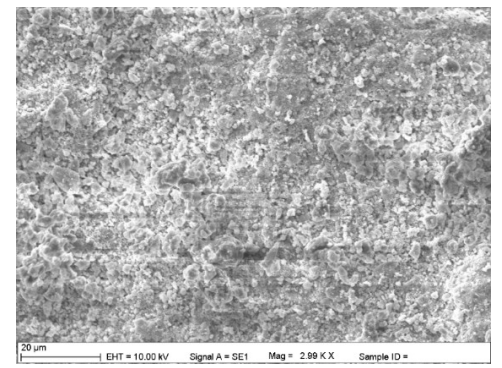

\section{Adsorption Studies}

The uptake of VBR dye from aqueous solutions with CE was investigated. To provide maximum removal, the effects of parameters such as adsorbent amount, contact time, $\mathrm{pH}$, temperature, and ionic strength on adsorption capacity were investigated. The obtained data were evaluated with some kinetic and isotherm model parameters were calculated. In order to investigate the effect of $\mathrm{pH}$ on adsorption capacity, the $\mathrm{pH}$ of the dye solution was changed between 5-10, and adsorption capacity for CE was investigated. $50 \mathrm{~mL}$ of the dye solution at a concentration of $100 \mathrm{mg} / \mathrm{L}$ was treated with $0.1 \mathrm{~g}$ of adsorbent. The adsorbent amount was studied in the range of 0.02 to $0.3 \mathrm{~g} / 50 \mathrm{~mL}$ VBR dye at $\mathrm{pH}$ 9.0. The effect of contact time on adsorption capacity was investigated at 3 various temperatures $\left(20,30\right.$, and $\left.40^{\circ} \mathrm{C}\right)$ in the range of 5-90 minutes.

Adsorption capacity and adsorption yield (\%) were calculated by the following equations:

$$
\begin{gathered}
q_{e}=\frac{V\left(C_{i}-C_{e}\right)}{m} \\
\text { Adsorption yield }(\%)=\frac{C_{i}-C_{e}}{C_{i}} \times 100
\end{gathered}
$$

$$
\begin{array}{ll}
\text { where } & \\
\mathrm{q}_{\mathrm{e}} & \text { : Adsorption Capacity }(\mathrm{mg} / \mathrm{g}) \\
\mathrm{C}_{\mathrm{i}} & \text { : Initial adsorbate concentration }(\mathrm{mg} / \mathrm{L}) \\
\mathrm{C}_{\mathrm{e}} & : \text { Equilibrium adsorbate concentration }(\mathrm{mg} / \mathrm{L}) \\
\mathrm{V} & : \text { The volume of dye solution }(\mathrm{L}) \\
\mathrm{m} & \text { : Amount of adsorbent }(\mathrm{g})
\end{array}
$$

\section{RESULTS AND DISCUSSION}

\section{Characterization of Adsorbent}

In the SEM micrograph of CE before adsorption (Fig.1a), a porous and coarse structure was observed, whereas after the adsorption (Fig. 1b), the porous structure became plate-like and the coarse appearance disappeared. This was interpreted as VBR adhering to the adsorbent surface and altering surface morphology.

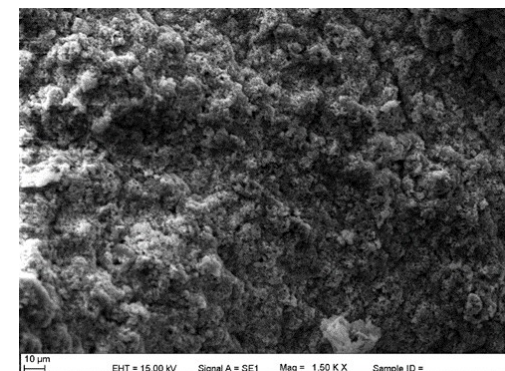

Figure 1: SEM pictogram a)before adsorption, b) after adsorption. 
FTIR spectroscopy was performed in the range of $400-4000 \mathrm{~cm}^{-1}$ to study the biosorption of VBR on CE. On the FTIR spectrum of CE the peaks at 1403 and $869 \mathrm{~cm}^{-1}$ belong to the $\mathrm{CO}_{3}{ }^{2-}$ anion (27).

\section{Effect of pH}

Within the scope of the study, firstly, the $\mathrm{pH}$ point where optimum adsorption capacity is optimum was investigated. Since VBR dye was dissolved in acidic $\mathrm{pH}$ regions, it was studied in regions higher than $\mathrm{pH}$ 5. Due to the possibility of interaction with the electron density regions of $\mathrm{VBR}$, the $\mathrm{pH}$ was not studied at points higher than 10 . As can be seen from the figure, while the adsorption capacity increased in the range of $\mathrm{pH} 5-8$, no significant increase was observed in the range of $\mathrm{pH}$ 8-10. According to these results, the optimum $\mathrm{pH}$ point was chosen as 9. Furthermore, considering the high calcium carbonate content of the eggshell, a primary point of $\mathrm{pH} 9$ is considered to be an optimal choice.

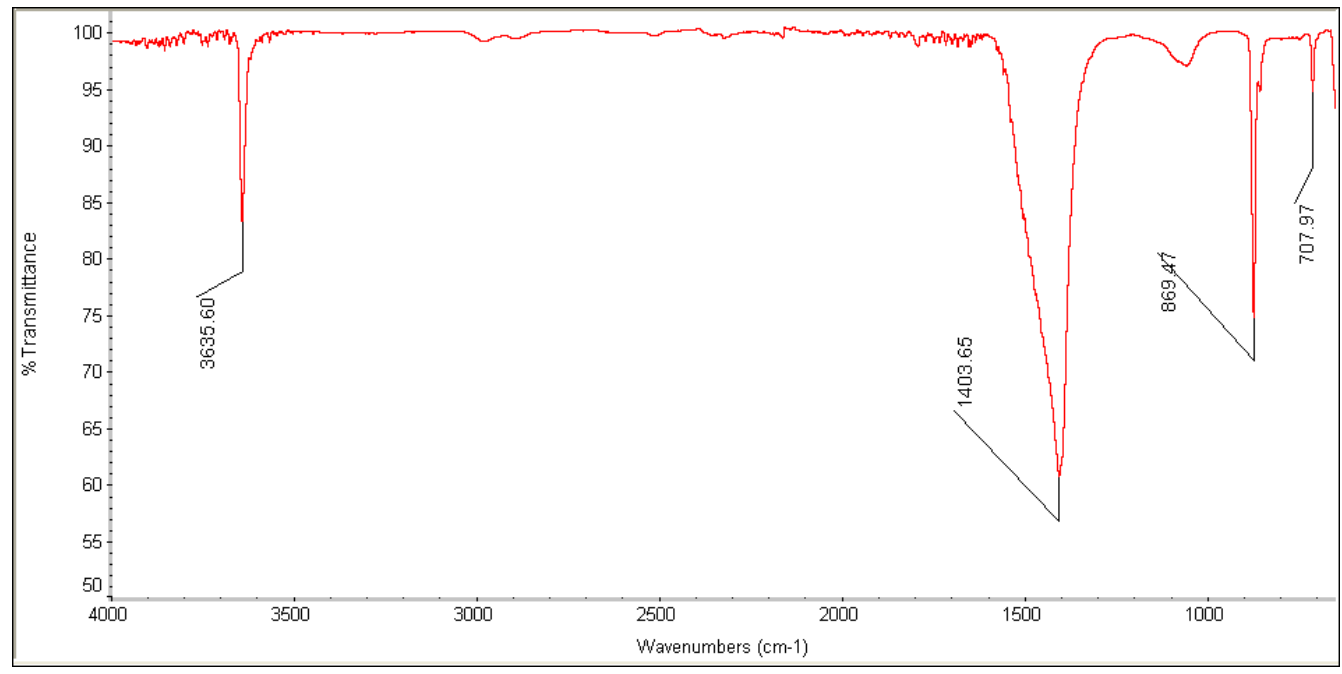

Figure 2: FT-IR Spectrum of calcinated eggshell.

\section{Effect of Adsorbent Amount}

To optimize adsorbent amount, the adsorbent amount of $0.4-0.6 \mathrm{~g}$ was investigated (Figure 3). A very high extraction rate of $94 \%$ was achieved, even at an adsorbent amount of $0.4 \mathrm{~g}$. In the adsorbent amount higher than $3.0 \mathrm{~g}$; a $100 \%$ removal was obtained.

\section{Interaction Time}

As seen in Figure 4, the effect of the interaction time was examined at 3 different temperatures (20, $30,40{ }^{\circ} \mathrm{C}$ ) in the range of $5-90$ minutes. The adsorption capacity values remained almost constant when the interaction time was increased from 5 minutes to 90 minutes. q value showed a very low decrease from 26 to 25 with increasing temperature. Optimum interaction time was determined as 5 minutes.

\section{Adsorption Kinetics}

The adsorption kinetics is a theoretical basis that determines the time required to establish an adsorption equilibrium. Many kinetic models have been developed to determine the mechanisms of adsorption, such as mass transfer and chemical reaction. The most common kinetic models in the literature are the pseudo-first-order kinetic model (Eq. 2) proposed by Lagergren (28) is the pseudosecond-order kinetic model (Eq. 3) proposed by Ho (29) and the interparticle diffusion equation model for Weber-Morris's (30) mass transfer mechanism (Eq. 4). The equations of kinetic models are as follows: 


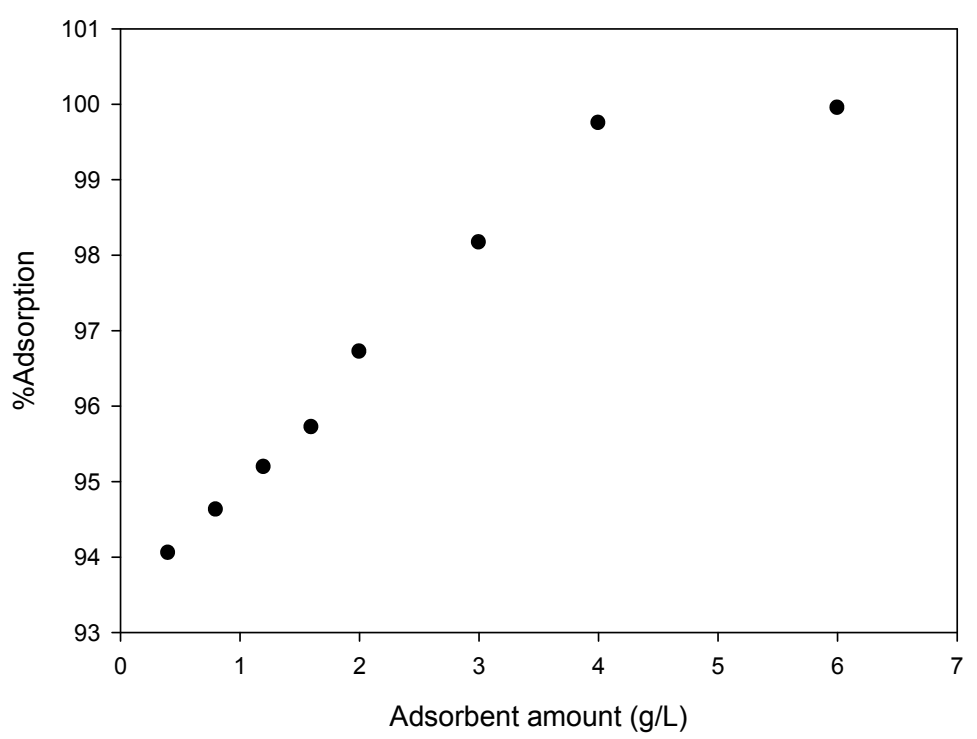

Figure 4: The effect of adsorbent amount on adsorption yield.

In this study, time-dependent data in the adsorption of calcined eggshell and VBR dye were evaluated by pseudo-first-order and pseudo-second-order kinetic models and intra-particle diffusion models. Some constants and $r^{2}$ values of the models are given in Table 1.

According to the results obtained from pseudo-firstorder kinetic model studies; $r^{2}$ values (Table 1 ) are in the range of $0.959-0.997$. According to the results obtained, it showed that the change was linear. But, $\mathrm{q}_{\mathrm{e}}$ values calculated using $\mathrm{y}$-intercept did not correspond to values obtained with Pseudo-First-Order

$$
q_{t}=q_{e}\left(1-\exp ^{-k 1}\right)
$$

Pseudo-Second-Order

Weber-Morris's mechanism

mass

transfer

$$
q_{e}=\left(\frac{k_{2} q_{e}^{2} t}{1+k_{2} q_{e} t}\right)
$$

$$
q_{t}=k_{p} t^{1 / 2}+C
$$

where:
qe Adsorption capacity at equilibrium $(\mathrm{mg} / \mathrm{g}$ )
$\mathrm{q}_{\mathrm{t}} \quad$ Adsorption capacity at different times $(\mathrm{t})(\mathrm{mg} / \mathrm{g})$
$\mathrm{k}_{1} \quad$ Pseudo-first-order equilibrium rate constant $(1 / \mathrm{min})$
$\mathrm{k}_{2} \quad$ Pseudo-second-order equilibrium rate constant ( $\left.\mathrm{g} / \mathrm{mg} . \mathrm{min}\right)$
$\mathrm{k}_{\mathrm{p}} \quad$ Intra-particle diffusion constant $\left(\mathrm{g} / \mathrm{mg} \cdot \mathrm{min}^{1 / 2}\right)$
C constant for any experiment $(\mathrm{mg} / \mathrm{g})$. 
Table 1. Kinetic parameters for the adsorption of VBR dye onto CE.

\begin{tabular}{|c|c|c|c|c|c|c|c|c|c|c|c|}
\hline \multicolumn{2}{|l|}{ Temperature } & \multicolumn{3}{|c|}{ Pseudo-first-order } & \multicolumn{3}{|c|}{ Pseudo-second-order } & \multicolumn{4}{|c|}{ Intraparticle diffusion } \\
\hline & $\begin{array}{l}\mathrm{K}_{1} \\
\left(\min ^{-1}\right)\end{array}$ & $\begin{array}{l}\mathrm{q}_{\mathrm{e}} \\
(\mathrm{mg} \mathrm{g}-1)\end{array}$ & \multicolumn{2}{|r|}{$\begin{array}{l}\mathrm{R}^{2} \\
\left(\mathrm{~g} \mathrm{mg} \mathrm{min}^{-1}\right)\end{array}$} & $\mathrm{k}_{2}$ & \multicolumn{2}{|c|}{$\begin{array}{l}\mathrm{q}_{\mathrm{e}} \\
\left(\mathrm{mg} \mathrm{g}^{-1}\right)\end{array}$} & \multicolumn{2}{|c|}{$\begin{array}{l}\mathrm{k}_{\mathrm{p}} \\
\left(\mathrm{mg} \mathrm{g}^{-1} \mathrm{~min}^{1 / 2}\right)\end{array}$} & $\begin{array}{l}\mathrm{C} \\
\left(\mathrm{mg} \mathrm{g}^{-1}\right)\end{array}$ & $\overline{R^{2}}$ \\
\hline $20^{\circ} \mathrm{C}$ & $6.69 \times 10^{-2}$ & 0.470 & \multicolumn{2}{|r|}{0.959} & $2.76 \times 10^{1}$ & 27.020 & 0.999 & \multicolumn{2}{|l|}{0.047} & 26.372 & 0.935 \\
\hline $30{ }^{\circ} \mathrm{C}$ & $5.50 \times 10^{-2}$ & 0.364 & \multicolumn{2}{|r|}{0.989} & $3.01 \times 10^{-1}$ & 25.641 & 0.999 & \multicolumn{2}{|l|}{0.043} & 25.135 & 0.938 \\
\hline $40^{\circ} \mathrm{C}$ & $5.10 \times 10^{-2}$ & \multicolumn{2}{|l|}{0.324} & 0.997 & $3.08 \times 10^{-1}$ & 25.641 & 0.999 & 0.040 & \multicolumn{2}{|c|}{25.071} & 0.961 \\
\hline \multicolumn{2}{|l|}{ Temperature } & \multicolumn{3}{|c|}{ Langmuir } & \multicolumn{3}{|c|}{ Freundlich } & \multicolumn{4}{|c|}{ Dubinin-Radushkevich (D-R) } \\
\hline$\overline{{ }^{\circ} \mathrm{C}}$ & $\begin{array}{l}q_{\max } \\
\left(\mathrm{mol} \mathrm{g}^{-1}\right)\end{array}$ & $\begin{array}{l}\mathrm{K}_{\mathrm{L}} \\
\left(\mathrm{L} \mathrm{mol}{ }^{-1}\right)\end{array}$ & $r^{2}$ & $\mathrm{R}_{\mathrm{L}}$ & $\mathrm{n}$ & $\begin{array}{l}\mathrm{K}_{\mathrm{F}} \\
\left(\mathrm{L} \mathrm{g}^{-1}\right)\end{array}$ & $\mathrm{r}^{2}$ & $\begin{array}{l}\mathrm{q}_{\mathrm{m}} \\
\left(\mathrm{mol} \mathrm{g} \mathrm{g}^{1}\right)\end{array}$ & $\begin{array}{l}\beta \\
\left(\mathrm{mol}^{2} \mathrm{~kJ}^{2}\right)\end{array}$ & $r^{2}$ & $\begin{array}{l}\mathrm{E} \\
\left(\mathrm{kJ} \mathrm{mol}{ }^{-1}\right)\end{array}$ \\
\hline 20 & 100 & $58.8 \times 10^{-2}$ & 0.919 & 0.99 & 1.052 & 63.68 & 0.964 & 50.95 & $5.645 \times 10^{-8}$ & 0.959 & $29.76 \times 10^{2}$ \\
\hline 30 & 140 & $87.5 \times 10^{-2}$ & 0.917 & 0.99 & 1.584 & 51.62 & 0.912 & 31.75 & $1.663 \times 10^{-8}$ & 0.688 & $54.83 \times 10^{2}$ \\
\hline 40 & 140 & $87.5 \times 10^{-2}$ & 0.937 & 0.99 & 1.675 & 53.96 & 0.969 & 34.32 & $1.585 \times 10^{-8}$ & 0.810 & $56.16 \times 10^{2}$ \\
\hline
\end{tabular}




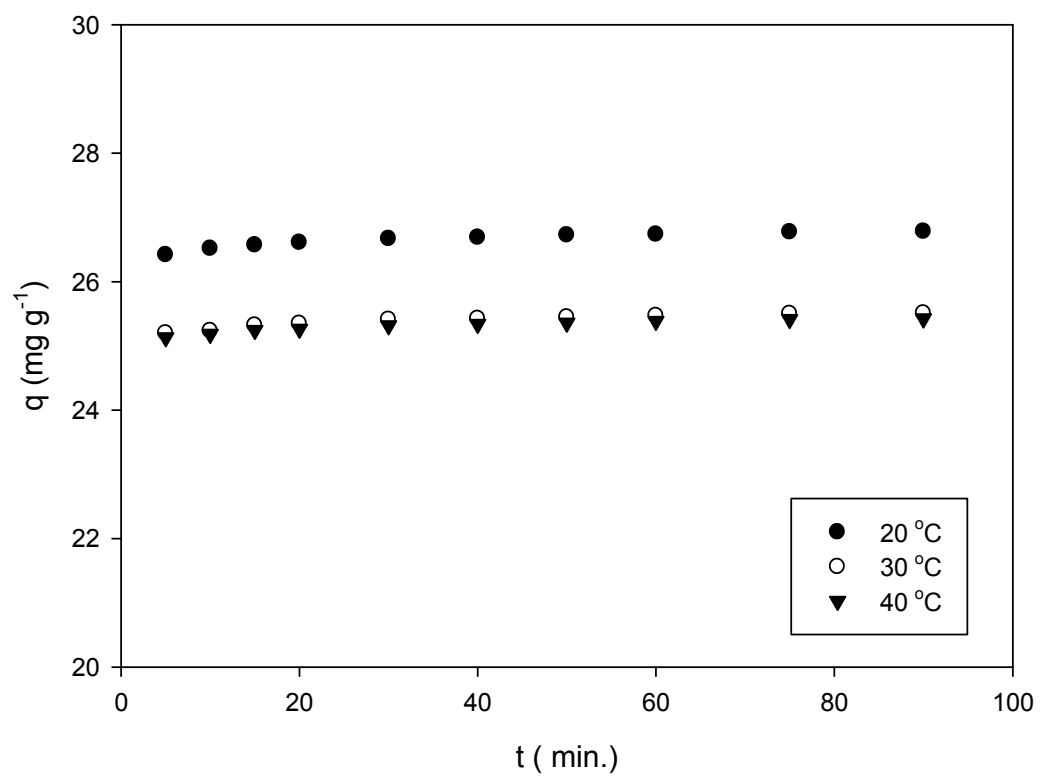

Figure 5: The effect of interaction time and temperature on adsorption yield.

Finally, experimental data was applied to the not adapt to the adsorption of the VBR dye on intraparticle diffusion model. According to the calcined eggshells. results obtained, it was found that this model does

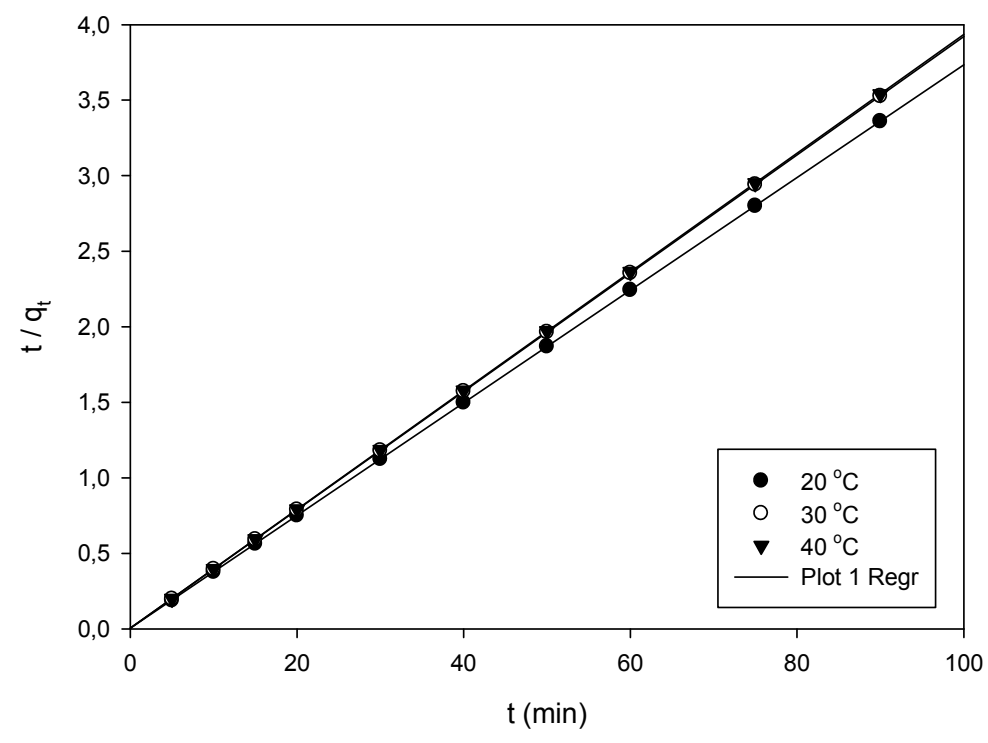

Figure 6: Pseudo-Second-order kinetic graphics.

\section{Adsorption Isotherms}

Adsorption in solution phase; temperature depends on concentration when adsorbent and adsorbate are kept constant. In this case, the equation showing the correlation of the amount of a substance bound to the surface at a constant temperature with the concentration of that substance in solution is called adsorption isotherm. The most common isotherms in practice are 
Langmuir, Freundlich, and Dubinin-Radushkevich $(D-R)$ isotherms.

According to the Langmuir isotherm model (31), when a molecule is adsorbed to the surface, no more adsorption occurs in the same region. Therefore, the Langmuir equation is valid only for a single layer coating formed by adsorption of a single molecule on a completely homogeneous surface. Langmuir equation;

$$
\frac{1}{q_{e}}=\frac{1}{q_{\max }}+\left(\frac{1}{q_{\max } K_{L}}\right) \times \frac{1}{C_{e}}
$$

is calculated by equation (6).

According to the Freundlich isotherm model (32), the adsorption zones on the surface of an adsorbent are heterogeneous. The equation of this isotherm model is expressed as follows.

$$
\ln q_{e}=\ln K_{F}+\frac{1}{n} \ln C_{e}
$$

$\mathrm{q}_{\mathrm{e}}$ : Amount of substance adsorbed in equilibrium $(\mathrm{mg} / \mathrm{g})$

$q_{\max }$ : Max. single layer adsorption capacity (mg/ g)

$\mathrm{C}_{\mathrm{e}}$ : Amount of matter remaining without adsorption in equilibrium $(\mathrm{mg} / \mathrm{L})$

$\mathrm{K}_{\mathrm{F}} \quad$ : Freundlich isotherm constant

$\mathrm{K}_{\mathrm{L}} \quad$ : Langmuir isotherm constant

$\varepsilon \quad$ : Polanyi potential $\beta$ : The activity coefficient related to biosorption energy

The D-R isotherm model (33) is used to understand whether adsorption occurring on heterogeneous surfaces is physical or chemical. D$\mathrm{R}$ isotherm model equation:

$$
\ln q_{e}=\ln q_{m}-\beta \epsilon^{2}
$$

In this study, the results obtained in equilibrium for the adsorption of VBR dyes to the CE surface were analyzed according to the Langmuir, Freundlich, and Dubinin-Radushkevich isotherm models, respectively. Constant values and $r^{2}$ values of all isotherm models are given in Table 2 .

When the $r^{2}$ values of the adsorption data in Table 2 are compared, it is seen that the Freundlich isotherm model (Fig. 7) is the most suitable model for VBR adsorption.

The value of $n$ appears to be higher than 1 for all 3 temperatures. It shows that the adsorption mechanism occurs voluntarily.

\section{Salt Effect}

In order to investigate the effect of ionic strength on adsorption capacity, dye solutions containing $\mathrm{NaCl}$ salt with concentrations ranging from 0.01 to 0.4 mol. $\mathrm{L}^{-1}$ were prepared. The prepared solutions were mixed with the adsorbent during a 5 minute equilibrium period. The data obtained from the experiment are given in Fig. 8 .

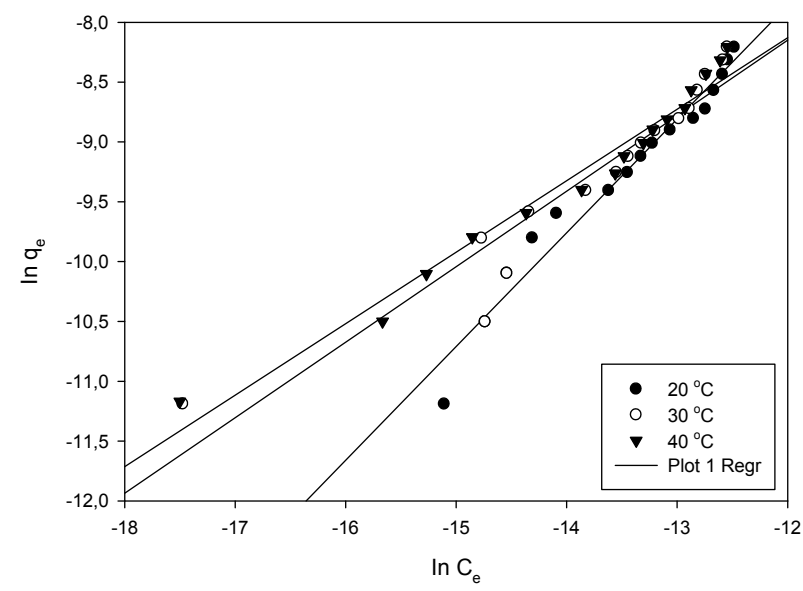

Figure 7: Freundlich isotherm graphics. 


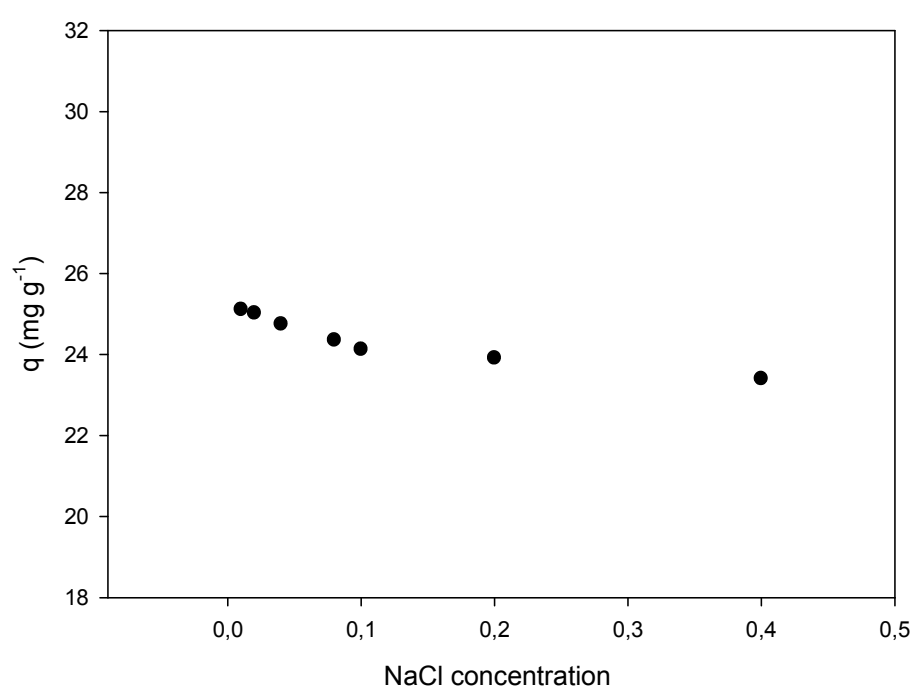

Figure 8: Salt effect on adsorption.

As it is understood from the figure, the increase of the concentration of salt in the medium, a small amount of adsorption capacity has been decreased. This situation indicates that ionic strength does not have a significant effect on the salt concentration range examined with calcined eggshell and VBR adsorption.

\section{Real wastewater}

The removal of the VBR dyestuff from the real wastewater environment was investigated in optimum conditions obtained by experimental studies. For this purpose, VBR dyestuff was added to the wastewater taken from the outlet water of a factory. In the adsorption study with real wastewater under optimum experimental conditions, $73.52 \%$ removal was observed. This value is very close to the efficiency obtained with synthetic solutions. This situation indicates that other components in the wastewater environment are not in competition with the VBR dyestuff to bind to the active sites on the adsorbent surface under the conditions under study. Thus, it has been revealed that the VBR dyestuff in wastewater can be removed from the environment with a small decrease in the adsorption efficiency with calcined eggshells.

\section{CONCLUSION}

In this study, the optimum $\mathrm{pH}$ value was determined as 6.0. The optimum $\mathrm{pH}$ value determined is also close to the initial $\mathrm{pH}$ of the dye solution (original dye solution $\mathrm{pH}=5.62$ ). Adsorption equilibrium has been established in a short time like 5 minutes. The adsorption process is best explained by the Freundlich isotherm model and the pseudo-second-order kinetic model. $73.52 \%$ eggshell is thought to be a very effective adsorbent due to its abundance and waste in nature and high adsorption capacity. Removal was achieved under optimum adsorption conditions in a real wastewater environment.

\section{ACKNOWLEDGMENTS}

This study was supported by the Scientific Research Projects Department of Hitit University (Project no: FEF01.13.009)

\section{REFERENCES}

1. Chen C-Y, Wang G-H, Tseng I-H, Chung Y-C. Analysis of bacterial diversity and efficiency of continuous removal of Victoria Blue $R$ from wastewater by using packed-bed bioreactor. Chemosphere. 2016;145:17-24.

2. Vaidya A. Environmental pollution during chemical processing of synthetic fibers. Colourage. $1982 ; 14: 3-10$

3. Ayed L, Chaieb K, Cheref A, Bakhrouf A. Biodegradation and decolorization of triphenylmethane dyes by Staphylococcus epidermidis. Desalination. 2010;260(1-3):137-46.

4. Azmi W, Sani RK, Banerjee UC. Biodegradation of triphenylmethane dyes. Enzyme and microbial technology. 1998;22(3):185-91.

5. Belpaire C, Reyns T, Geeraerts C, Van Loco J. Toxic textile dyes accumulate in wild European eel Anguilla anguilla. Chemosphere. 2015;138:784-91. 
6. Black JJ, Holmes M, Dymerski PP, Zapisek WF. Fish tumor pathology and aromatic hydrocarbon pollution in a Great Lakes estuary. Hydrocarbons and halogenated hydrocarbons in the aquatic environment: Springer; 1980. p. 559-65.

7. Chen K, Lu C, Chang T, Lai Y, Wu C, Chen C. Comparison of photodegradative efficiencies and mechanisms of Victoria Blue R assisted by Nafioncoated and fluorinated $\mathrm{TiO} 2$ photocatalysts. Journal of hazardous materials. 2010;174(1-3):598-609.

8. Cho BP, Yang T, Blankenship LR, Moody JD, Churchwell $M$, Beland FA, et al. Synthesis and characterization of $\mathrm{N}$-demethylated metabolites of malachite green and leucomalachite green. Chemical research in toxicology. $2003 ; 16(3): 285-$ 94.

9. Demirbaş O, Alkan M, Doğan $M$. The removal of Victoria blue from aqueous solution by adsorption on a low-cost material. Adsorption. $2002 ; 8(4): 341-9$.

10. Rajabi HR, Khani O, Shamsipur M, Vatanpour V. High-performance pure and Fe3+-ion doped ZnS quantum dots as green nanophotocatalysts for the removal of malachite green under UV-light irradiation. Journal of hazardous materials. 2013;250:370-8.

11. Almeida LC, Silva BF, Zanoni MV. Photoelectrocatalytic/photoelectro-Fenton coupling system using a nanostructured photoanode for the oxidation of a textile dye: kinetics study and oxidation pathway. Chemosphere. 2015;136:6371.

12. Huang $S-T$, Jiang $Y-R$, Chou $S-Y$, Dai $Y-M$, Chen C-C. Synthesis, characterization, photocatalytic activity of visible-light-responsive photocatalysts BiOxCly/BiOmBrn by controlled hydrothermal method. Journal of Molecular Catalysis A: Chemical. 2014;391:105-20.

13. Jiang $Y-R$, Chou S-Y, Chang J-L, Huang S-T, Lin $\mathrm{H}-\mathrm{P}$, Chen C-C. Hydrothermal synthesis of bismuth oxybromide-bismuth oxyiodide composites with high visible light photocatalytic performance for the degradation of CV and phenol. RSC Advances. 2015;5(39):30851-60.

14. Lee WW, Lu C-S, Chuang C-W, Chen Y-J, Fu J$Y$, Siao C-W, et al. Synthesis of bismuth oxyiodides and their composites: characterization, photocatalytic activity, and degradation mechanisms. RSC Advances. 2015;5(30):2345063.
15. Rajabi HR, Farsi M. Quantum dot based photocatalytic decolorization as an efficient and green strategy for the removal of anionic dye. Materials Science in Semiconductor Processing. 2015;31:478-86.

16. Roushani M, Mavaei M, Rajabi HR. Graphene quantum dots as novel and green nano-materials for the visible-light-driven photocatalytic degradation of cationic dye. Journal of Molecular Catalysis A: Chemical. 2015;409:102-9.

17. Geetha $P$, Latha M, Koshy M. Biosorption of malachite green dye from aqueous solution by calcium alginate nanoparticles: equilibrium study. Journal of Molecular Liquids. 2015;212:723-30.

18. Oguntimein GB. Biosorption of dye from textile wastewater effluent onto alkali treated dried sunflower seed hull and design of a batch adsorber. Journal of Environmental Chemical Engineering. 2015;3(4):2647-61.

19. Erol K, Köse K, Köse DA, Sızır Ü, Tosun Satır İ, Uzun L. Adsorption of Victoria Blue R (VBR) dye on magnetic microparticles containing Fe (II)-Co (II) double salt. Desalination and Water Treatment. 2016;57(20):9307-17.

20. Sun D, Zhang $X$, Wu Y, Liu X. Adsorption of anionic dyes from aqueous solution on fly ash. Journal of hazardous materials. 2010;181(13):335-42.

21. Madrakian T, Afkhami A, Ahmadi M. Adsorption and kinetic studies of seven different organic dyes onto magnetite nanoparticles loaded tea waste and removal of them from wastewater samples. Spectrochimica Acta Part A: Molecular and Biomolecular Spectroscopy. 2012;99:102-9.

22. Singh SA, Vemparala B, Madras G. Adsorption kinetics of dyes and their mixtures with Co3O4ZrO2 composites. Journal of Environmental Chemical Engineering. 2015;3(4):2684-96.

23. Gamoudi S, Srasra E. Adsorption of organic dyes by HDPy+-modified clay: Effect of molecular structure on the adsorption. Journal of Molecular Structure. 2019;1193:522-31.

24. Gupta K, Khatri OP. Fast and efficient adsorptive removal of organic dyes and active pharmaceutical ingredient by microporous carbon: Effect of molecular size and charge. Chemical Engineering Journal. 2019;378:122218. 
25. Nyamukamba P, Tichagwa L, Okoh O, Petrik L. Visible active gold/carbon co-doped titanium dioxide photocatalytic nanoparticles for the removal of dyes in water. Materials Science in Semiconductor Processing. 2018;76:25-30.

26. Al-Ghouti MA, Salih NR. Application of eggshell wastes for boron remediation from water. Journal of Molecular Liquids. 2018;256:599-610.

27. Prabakaran K, Rajeswari S. Spectroscopic investigations on the synthesis of nanohydroxyapatite from calcined eggshell by hydrothermal method using cationic surfactant as template. Spectrochimica Acta Part A: Molecular and Biomolecular Spectroscopy. 2009;74(5):112734.

28. Lagergren S, Lagergren S, Lagergren S, Sven K. Zurtheorie der sogenannten adsorption gelösterstoffe. 1898 .
29. Ho Y, McKay G. Kinetic models for the sorption of dye from aqueous solution by wood. Trans IChemE. 1998;76(B):183-91.

30. Weber WJ, Morris JC. Kinetics of adsorption on carbon from solution. Journal of the sanitary engineering division. 1963;89(2):31-60.

31. Langmuir I. The adsorption of gases on plane surfaces of glass, mica and platinum. Journal of the American Chemical society. 1918;40(9):1361403.

32. Freundlich $\mathrm{H}$. Über die adsorption in lösungen. Zeitschrift für physikalische Chemie. 1907;57(1):385-470.

33. Radushkevich $M$. The equation of the characteristic curve of the activated charcoal USSR Phys. Chem Sect. 1947;55:331. 